\title{
REVIEW
}

\section{Pro/con debate: Continuous versus intermittent dialysis for acute kidney injury: a never-ending story yet approaching the finish?}

\author{
Raymond Vanholder ${ }^{*}$, Wim Van Biesen', Eric Hoste ${ }^{2}$ and Norbert Lameire'
}

\begin{abstract}
The question of whether renal replacement therapy should be applied in an intermittent or continuous mode to the patient with acute kidney injury has been the topic of several controlled studies and metaanalyses. Although continuous renal replacement therapy (CRRT) has a theoretical advantage due to offering the opportunity to remove excess fluid more gradually, none of the several outcome studies that have been undertaken in the meanwhile was able to demonstrate its superiority over intermittent renal replacement therapy (IRRT). In the present article, therefore, questions are raised regarding which are the specific advantages of each strategy, and which are the specific populations that might benefit from their application. Although several advantages have been attributed to CRRT - especially more hemodynamic stability allowing more adequate fluid removal, better recovery of renal function, and more efficient removal of small and large metabolites - none of these could be adequately proven in controlled trials. CRRT is claimed to be better tolerated in combined acute liver and kidney failure and in acute brain injury. IRRT is more practical, flexible and cost-effective, allows the clinician to discontinue or to minimize anticoagulation with bleeding risks, and removes small solutes such as potassium more efficiently in acute life-threatening conditions. Sustained low-efficiency daily dialysis is a hybrid therapy combining most of the advantages of both options.
\end{abstract}

\section{Introduction}

Few topics in nephrology have been the subject of so many randomized controlled trials (RCTs), meta-analyses and reviews than that of extracorporeal renal replacement in acute kidney injury (AKI). Since the introduction of hemodialysis as a valid treatment for renal failure by Kolff in the early 1940s [1], intermittent renal replacement therapy (IRRT) was offered as a bridge until recovery of kidney function; first in a low-efficient and therefore protracted version, later becoming progressively shorter. In the 1980s, Kramer and colleagues introduced continuous renal replacement therapy (CRRT) as an alternative, allowing blood purification 24 hours per day - at least in principle [2].

CRRT originally applied a simple concept without pumps or technology (continuous arteriovenous hemofiltration). Since this approach often lacked efficiency, however, machines containing blood pumps soon made their appearance (continuous venovenous hemofiltration). Whereas solute removal with IRRT at the origin essentially made use of diffusion - that is, gradientrelated molecule shifts in a liquid milieu from higher to lower concentration gradients - CRRT started as a convective strategy, driven by removal of solute-containing ultrafiltrate through large pores and its replacement by substitution fluid. With time, diffusion was also implied in CRRT by introducing additional pumps to the machines, while convective strategies became more widely applied in IRRT. Characteristics of CRRT and IRRT tended to converge further at the beginning of this century in a concept named sustained low-efficiency daily dialysis (SLEDD) [3], by applying IRRT mostly at lower blood and dialysate flows but at prolonged dialysis times. The term low efficiency is, however, in many cases a misnomer $[4,5]$. Sometimes, this strategy is also named prolonged intermittent renal replacement therapy.

It is difficult to find a uniform definition of SLEDD in the literature. In fact, one of the advantages of SLEDD lies in its flexibility both in terms of duration and of intensity. In the present text, the term SLEDD refers to any hemodialysis treatment performed with conventional

\footnotetext{
'Nephrology Section, Department of Internal Medicine, University Hospital, De Pintelaan 185, B9000 Gent, Belgium

Full list of author information is available at the end of the article
} 
dialysis machines over a longer time lapse than traditional intermittent hemodialysis (usually $\geq 5$ hours).

Already from the early days, the question was raised regarding which of CRRT or IRTT was related to better outcome. The general perception was that the continuous approach, due to its slow protracted nature, would result in better outcomes. At least seven published RCTs and three meta-analyses, however, were unable to demonstrate a difference in outcome between both approaches [6-15], with a reported relative risk of 0.99 in the most recent meta-analysis [15].

Some authors have pointed to flaws in the design of these RCTs [15]. Several of these biases were logistic, however, and in that case inherent to the very nature of the strategies implied [16] - such as the incapacity to enroll patients into continuous protocol arms due to unavailability of appropriate devices [10], or the impossibility to reach the preset exchange volume [11]. Logistical factors should thus also be taken into account when deciding on CRRT or IRRT [16]. Other biases skewing these RCTs are related to study design, conduct and reporting flaws.

In specific subpopulations and/or based on arguments other than outcome, however, one of these two approaches might still be preferable over the other. In the present pro/con debate, both the advantages and disadvantages of CRRT and IRRT will be reviewed.

Of note, all therapeutic strategies available should not be considered as competitors, but rather as alternatives, each of which might be applicable within the same unit and even the same patient, depending on the practical options at hand at a given moment and on the metabolic or the fluid balance needs of the patient.

\section{Pro continuous renal replacement therapy}

Several theoretical advantages have been attributed to CRRT over IRRT: more hemodynamic stability allowing more adequate fluid removal; better recovery of renal function; and more efficient removal of small and large metabolites. None of these assumptions, however, could consistently withstand the test of controlled clinical trial conditions.

\section{Hemodynamic stability and fluid removal}

Several controlled trials fail to consistently demonstrate better hemodynamic stability and/or superior vital parameters for CRRT $[6,7,10-12,17]$. In a meta-analysis from the Cochrane group published in 2007, mean arterial pressure was the only clinical hemodynamic parameter that was significantly higher with CRRT than with IRRT; the number of hypotension episodes was not different, however [14]. Another systematic review showed no nominal differences [13]. A third review found a suggestion that CRRT was superior with regard to episodes of hemodynamic instability $(P=0.03)$ [15], based on four studies - with the major effect coming from the study by Augustine and colleagues, in which the difference between both strategies was significant but the fall in mean arterial pressure amounted to only $2.6 \mathrm{mmHg}$ versus the start of treatment [6].

Overall, it can be concluded that if there is a hemodynamic benefit for CRRT, this nevertheless is not translated into differences of survival. Data also seem to suggest that part of the observed hemodynamic advantages of CRRT could be attributed to heat loss and hypothermia [12], improving venous return and blood pressure [18]. A similar effect can be obtained in IRRT by cooling dialysate, which has now become current practice in chronic hemodialysis [19] but applies to the AKI setting as well.

One problem potentially blurring the results of RCTs comparing CRRT and IRRT is the reluctance for including patients with major hemodynamic problems out of fear of instability in case of randomization to intermittent dialysis; this might result in the exclusion of the most unstable patients, reducing the differences among therapies.

A protracted treatment should allow removing fluid at a larger cumulative volume. CRRT allowed markedly more negative fluid balances in one RCT [6] but not in another [12].

In view of all of the uncertainties mentioned above and because of the physiological plausibility, fluid-overloaded patients are among those with the highest potential to benefit from CRRT or from IRRT in the SLEDD mode. CRRT has also been suggested to offer more possibilities for the administration of parenteral nutrition fluids [20] a suggestion, however, not confirmed in a prospective study [10].

\section{Preservation of renal function}

One of the major potential advantages of preserving hemodynamic stability is a positive effect on recovery of kidney function. When autoregulation is lost due to AKI, each new hypotensive episode decreases glomerular perfusion [21], causing recurrent focal ischemic injury and postponing recovery of kidney function according to some studies [22]. Each condition such as IRRT causing more hypotension might thus theoretically emanate in a slower recovery of kidney function and a larger number of renal deaths (nonrecovery of renal function resulting in chronic dialysis), and might also affect perfusion of other organ systems, such as the heart. Nevertheless, all controlled studies [6,8-11] and meta-analyses $[13,14,23]$ devoted to this aspect failed to demonstrate superiority of CRRT in this regard. For the sake of completeness, three observational trials suggested less evolution into chronic kidney disease stage 5 on dialysis (formerly endstage renal disease) with CRRT [24-26]. In view of the 
lack of a difference in five RCTs and three systematic reviews $[6,8-11,13,14,23]$, however, the evidence base offered by these uncontrolled trials is insufficient to overrule the controlled data.

\section{Solute removal}

Prolonging dialysis, even if dialyzer blood flow and dialysate flow are decreased proportionally, promotes solute removal due to better mobilization from extra-plasmatic compartments [4]. In line with these findings, it has been suggested that slow strategies result in more efficient removal.

A mathematical study compared the possibilities of removing the small solute urea with CRRT and IRRT. With CRRT, the threshold urea concentration could be maintained by increasing the fluid exchange volume in patients of all body weights up to a volume of more than $45 \mathrm{l} /$ day. For IRRT, it became impossible to reach the lowest threshold (blood urea nitrogen $60 \mathrm{mg} / \mathrm{dl}$ ) for a body weight in excess of $90 \mathrm{~kg}$ [27] but the treatment time was not allowed to exceed 4 hours per day in spite of blood flows of only $200 \mathrm{ml} /$ minute. Of note, the way the modalities were introduced in the calculations (high volume for CRRT vs. a fixed limitation to 4 hours and an intermediate blood flow for IRRT) is more important for the result than the modality per se: for IRRT, the target could easily have been reached by assuming longer treatment times and/or higher blood flows.

Real-life comparisons of small molecule removal are scarce. In one study, day-by-day urea and creatinine levels were lower with CRRT than IRRT [9]. In other studies, daily urea clearances or concentrations were the same with both approaches $[10,11]$; while in a third study, only creatinine and not urea decreased more with CRRT [12].

Removal of cytokines might be more clinically relevant than removal of urea or creatinine in a population that is in general very sick and inflamed. At least two studies confirmed this cytokine removal by CRRT, by adsorption on the membrane, and/or by transmembrane elimination $[28,29]$. In one study, TNF $\alpha$ could be found in the ultrafiltrate, but there was no significant decrease in plasma concentration for this compound, as well as for all nine other cytokines or cytokine receptors under consideration [28]. In another study, removal was rapidly overwhelmed by generation once the membrane surfaces were saturated - and removal affected proinflammatory cytokines as much as their anti-inflammatory soluble receptors or antagonists [29]. It is conceivable that the same risk of indiscriminating removal applies also to anti-inflammatory cytokines such as IL-4, IL-10 or 1L-18. In addition, since removal is essentially by adsorption, filters need to be changed regularly, increasing the cost and decreasing the continuity of the treatment. Of note, removal of cytokines and other large molecules can be obtained just as well, if not better, with IRRT or SLEDD, under the condition that open membranes with large pore size (so-called high-flux membranes) are applied.

The impact of increasing solute removal above currently applied levels can be questioned, as at least two large multicenter studies [30,31] and one meta-analysis [32] failed to demonstrate a survival advantage of more efficient removal over standard removal. A potential reason for this failure could be that the higher intensity of solute removal also has a downside, such as greater removal of drugs resulting in inadequate drug concentrations (for example, of antimicrobials) or more electrolyte disturbances [11].

One factor negatively affecting removal with CRRT is the frequent necessity to interrupt the procedure - for example, because of filter clotting, which occurs more frequently in CRRT than in IRRT. Average delivery of treatment per day with CRRT was reported to be only 19.5 hours [3,33], with observed individual values as low as 13.4 hours per day [3].

\section{Specific patient populations benefiting from CRRT}

Although the evidence is contradictory (see above), the application of CRRT in combating severe fluid overload can be defended. Other specific conditions in which CRRT has been proposed as the preferred option are combined acute renal and hepatic failure because of a beneficial impact on cardiovascular stability and intracranial pressure $[34,35]$, and acute brain injury because of prevention of cerebral edema [36].

\section{Peritoneal dialysis}

Peritoneal dialysis is an often neglected continuous modality in AKI, although it can especially be of help in hemodynamically unstable and fragile patients, in those with enhanced bleeding risk, and in children [37], especially neonates and small children with postcardiac surgery AKI and hemolytic uremic syndrome. Of note, up to now only two RCTs have compared peritoneal dialysis with hemodialysis or related strategies in AKI. In a Vietnamese study on infected patients, continuous hemofiltration was superior - but the applied peritoneal dialysis strategy was not comparable with what is currently state of the art [38]. The other study, in a supplement issue, showed no differences [37] - here also, the peritoneal dialysis regime was unlikely to be sufficient to obtain satisfactory solute clearance.

\section{Pro intermittent renal replacement therapy}

From the above, it appears that very few arguments based on controlled clinical studies suggest superiority of CRRT above IRRT or vice versa. Except for a number of specific indications, each one of these two strategies as well as any intermediate possibility lying in between (that is, 
SLEDD in all its forms - see below) can clinically speaking be considered a valid option for dialysis treatment of the average patient with AKI [16].

When the arguments in favor of IRRT are to be summed up, therefore, one might consider practical elements such as user-friendliness or limitation of expenses, as much as clinical factors benefiting its use in specific subpopulations. Consequently, the following benefits of IRRT will be discussed: practicality and flexibility of application; limitation of expenses; restriction of bleeding complications; and small solute removal in acute lifethreatening conditions.

\section{Practicality and flexibility of application}

IRRT can be performed with the same technical infrastructure as that available in the unit for chronic intermittent hemodialysis, allowing more flexibility for the treatment of the unpredictable and ever-fluctuating number of AKI patients in need of dialysis [16]. This approach also allows treatment of several patients per day with the same device, in contrast to CRRT where one dedicated device is to be attributed to each single patient. IRRT also allows more liberty for patient care and investigations outside the treatment and monitoring unit, by offering a dialysis-free period, without loss of dialysis time or adequacy. The extra free time also offers opportunities to mobilize the patients during their time off dialysis, in contrast to more continuous strategies whereby the relative immobilization may result in more severe muscle wasting and a higher risk of nosocomial respiratory tract infections.

IRRT has also another advantage: machines can be used in an extended protracted mode when needed, and the treatment time can be decreased coupled to an increase in efficacy when the condition of the patient improves. This contrasts with CRRT machines, which do not allow an increase of the intensity of the treatment to allow shorter treatments.

\section{Limitation of expenses}

There is an increasing trend to take cost into account for clinical therapeutic decisions. This is more the case, if, as concluded from the data above, a clear distinction based on outcome studies is difficult.

In some early clinical trials in which cost estimation was not the main purpose, little difference in expense was demonstrated [9,39]. More recently, several specific cost analyses have been developed [33,40-43]. Most of these studies were limited to one single center or a few centers, and in all of them IRRT was less costly than CRRT [33,4042]. In one study the cost of CRRT was more than double of that of IRRT [42]. Of course, analyses performed in single health service delivery settings may be biased because data may be context specific. A recent transcontinental multicenter and multinational analysis in the context of the Beginning and Ending Supportive Therapy for the Kidney study, however, evaluated cost in the intensive care unit (ICU) and revealed substantial differences in cost by region, but in addition indicated a higher trend for global cost of CRRT for most of the locations where data were collected. The median difference was US $\$ 289.6$ per day in disfavor of CRRT [43]. The main differences could be attributed to fluid replacement and the extracorporeal circuit; reducing the substitution volume to $<25 \mathrm{ml} /$ minute $/ \mathrm{kg}$, as recently suggested [44], diminished cost only by US $\$ 67.2$ per day [43]. Although the general trend for the median cost of nursing staff was slightly in disfavor of IRRT, results were highly variable and depended on whether or not extra staff were deployed for the application of CRRT. Overall, dialysate and replacement fluid costs and extracorporeal circuit costs were in favor of IRRT worldwide, irrespective of the continent where the analysis was undertaken.

Overall, however, the data from all these studies taken together point to a cost advantage for IRRT. Of note, although the Beginning and Ending Supportive Therapy for the Kidney study is an important step forward as it contains comparative analysis from 23 countries and five continents, assessments were center-based rather than patient-based. Cost prediction was for that matter focused on general perception rather than on individual data. Further analyses might include patient-to-patient assessments of real costs comprising relative work load and related expenditures.

\section{Restriction of bleeding complications}

Owing to the continuous contact of the filter with blood, CRRT necessitates appropriate anticoagulation 24 hours per day - increasing the bleeding risk, especially in those who had a trauma or recent surgery or who suffer from medical diseases prone to bleeding. This drawback can be solved by regional citrate anticoagulation $[45,46]$, but this option depends on skilled personnel and any mistake or technical problem may have grave consequences, such as life-threatening hypocalcemia. In units with dedicated personnel, however, outcomes with citrate might be beneficial [47]. Owing to high diffusive clearance, citrate anticoagulation is more easily applicable and less dangerous in IRRT as compared with in CRRT.

In a large RCT, bleeding complications were more frequent in the CRRT group and were the major reason for switching modalities from CRRT to IRRT [11]. With IRRT, anticoagulation may be omitted or minimized, and does not take place all day long. Kumar and colleagues found that patients on IRRT versus those on CRRT had less need for anticoagulation, and that a much larger proportion of patients could be treated without coagulation at all [48]. Additionally, and in spite of continuous 
anticoagulation, filter clotting tends to occur more frequently with CRRT than with IRRT [14].

\section{Small solute removal in acute life-threatening conditions} Although in general the adequacy of IRRT and CRRT depends on the actual conditions under which the modalities are applied, IRRT has a more efficient immediate effect than CRRT when small water-soluble compounds are to be removed in an acute lifethreatening condition because of the high blood and dialysate flows that can be achieved, resulting in a superior clearance and mass transfer per time unit [49]. This is highly relevant for severe hyperkalemia, especially in the initiation phase of AKI and in patients with rhabdomyolysis, in whom potassium release from the compressed and necrotized muscle may last for several days [50]. For that reason IRRT has been used extensively in the aftermath of disasters [51,52]. Other specific indications profiting from high solute removal are tumor lysis syndrome and certain cases of poisoning.

\section{Specific patient populations benefiting from intermittent renal replacement therapy}

IRRT might be a useful strategy in any patient with bleeding or bleeding risk, including those after recent surgery, and is indicated for the acute treatment of hyperkalemia and rhabdomyolysis. For the global ICU population, there seems to be no clinical preference for either one of both IRRT or CRRT, but assets in favor of IRRT are its practical flexibility and cost-effectiveness.

\section{Conclusions - towards slow long-extended daily dialysis}

Since both CRRT and IRRT are perfectly acceptable for clinical therapeutic use, by extrapolation the same might also apply to all intermediary solutions that lie in between.

SLEDD is a hybrid therapy, offering advantages of both CRRT and IRRT $[3,48,53]$, combining protracted treatment with an intermittent time scheme, usually applying IRRT machines, and representing a high-tech return to the roots of dialysis as applied in the early days by Kolff [1]. The major advantages of this approach are the flexibility of the system, the reduced costs as compared with CRRT, and the possibilities for application with low or even absent anticoagulation [54].

Comparative studies between SLEDD and CRRT resulted in similar indices of adequacy and a similar hemodynamic response $[3,48,55,56]$. In one study of 16 patients, acidosis was slightly higher and blood pressure was lower with SLEDD, but only at 2 hours after the start of treatment [57,58]. Of note, blood pressure was nonsignificantly lower by some $8 \mathrm{mmHg}$ with SLEDD than before treatment onset. The application of the
Genius batch dialysis system (Fresenius Medical Care, Bad Homburg, Germany), whereby dialysate is warmed only before the start of the session and allowed subsequently to cool slowly, may have an extra positive hemodynamic impact [59]. Flexibility lies both in the duration of and in the intensity of the treatment. In SLEDD, the blood flow, the dialysate flow and often also the rate of ultrafiltration can be tailored to the actual needs of the patient - in contrast to CRRT, where, due to technical constraints, in practice the maximal intensity is limited. SLEDD can thus be performed as a low-intensive and prolonged treatment but also as a shorter highly intensive modality, for each option with the same machine.

Because of the adequate removal capacity, the possibility that drugs are more effectively cleared than with traditional short IRRT should be taken into account, so that the classically recommended drug doses might be not applicable [60,61]; especially, antibiotics might be affected substantially - if possible, concentrations should be measured regularly for therapeutic monitoring. The same might apply, however, for CRRT [62-64].

Most of these conclusions are extrapolated from comparisons between IRRT and CRRT (see above) with SLEDD as an intermediate strategy. Controlled outcome trials comparing SLEDD with the more traditional approaches in large populations are to the best of our knowledge lacking at this moment. Although such a comparison was not the primary aim of the study, however, indirect evidence from the Veterans Adminstration trial suggests SLEDD to yield similar outcomes to CRRT and IRRT [30]. Further studies exploring potential benefits of each modality are awaited. In view of the heterogeneity of the ICU population and the strong influence of center experience with individual modalities, however, it is unlikely that a final answer will ever be obtained.

In summary, CRRT and IRRT are equivalent dialysis strategies regarding outcome for the ICU patient with AKI, with a few exceptions for specific problems that are a direct indication for either one or the other strategy. Assets evoked in the present article in favor of CRRT are its potential for more fluid removal in severely overloaded patients, its potential - however hardly proven - for better hemodynamic stability in severely unstable patients, and its better tolerability in combined acute liver and kidney failure and in acute brain injury. IRRT is more practical, flexible and cost-effective, allows the clinician to discontinue or to minimize anticoagulation with bleeding risks, and removes small solutes such as potassium more efficiently in acute life-threatening conditions. SLEDD is a hybrid therapy combining most of the advantages of both options. All these options should not be considered as competitors, but rather as 
This article is part of the series Renal replacement therapy, edited by John Kellum and Lui Forni.

alternatives that may be switched in the same patient depending on his/her condition and the ad hoc possibilities at a given moment in a given unit. From the practical point of view, among these modalities, SLEDD seems to offer the highest flexibility to tailor treatment according to the individual needs of the patient.

\section{Abbreviations}

AKI, acute kidney injury; CRRT, continuous renal replacement therapy; ICU, intensive care unit; IL, interleukin; IRRT, intermittent renal replacement therapy; $\mathrm{RCT}$, randomized controlled trial; SLEDD, sustained low-efficiency daily dialysis; TNF, tumor necrosis factor.

\section{Competing interests}

The authors declare that they have no competing interests.

\section{Author details}

'Nephrology Section, Department of Internal Medicine, University Hospital, De Pintelaan 185, B9000 Gent, Belgium. 'Intensive Care Unit, University Hospital, De Pintelaan 185, B9000 Gent, Belgium.

Published: 28 January 2011

\section{References}

1. Nose Y: Dr. Willem J. Kolff: the godfather of artificial organ technologies (February 14, 1911-February 11, 2009). Artif Organs 2009, 33:389-402.

2. Kramer P, Schrader J, Bohnsack W, Grieben G, Grone HJ, Scheler F: Continuous arteriovenous haemofiltration. A new kidney replacement therapy. Proc Eur Dial Transplant Assoc 1981, 18:743-749.

3. Kumar VA, Craig M, Depner TA, Yeun JY: Extended daily dialysis: a new approach to renal replacement for acute renal failure in the intensive care unit. Am J Kidney Dis 2000, 36:294-300.

4. Eloot S, Van Biesen W, Dhondt A, Van de Wynkele H, Glorieux G, Verdonck P, Vanholder R: Impact of hemodialysis duration on the removal of uremic retention solutes. Kidney Int 2008, 73:765-770.

5. Mushatt DM, Mihm LB, Dreisbach AW, Simon EE: Antibiotic dosing in slow extended daily dialysis. Clin Infect Dis 2009, 49:433-437.

6. Augustine JJ, Sandy D, Seifert TH, Paganini EP: A randomized controlled trial comparing intermittent with continuous dialysis in patients with ARF. Am J Kidney Dis 2004, 44:1000-1007.

7. Gasparovic V, Filipovic-Grcic I, Merkler M, Pisl Z: Continuous renal replacement therapy (CRRT) or intermittent hemodialysis (IHD) - what is the procedure of choice in critically ill patients? Ren Fail 2003, 25:855-862.

8. Lins RL, Elseviers MM, Van der Niepen P, Hoste E, Malbrain ML, Damas P, Devriendt J: Intermittent versus continuous renal replacement therapy for acute kidney injury patients admitted to the intensive care unit: results of a randomized clinical trial. Nephrol Dial Transplant 2009, 24:512-518.

9. Mehta RL, McDonald B, Gabbai FB, Pahl M, Pascual MT, Farkas A, Kaplan RM: A randomized clinical trial of continuous versus intermittent dialysis for acute renal failure. Kidney Int 2001, 60:1154-1163.

10. Uehlinger DE, Jakob SM, Ferrari $P$, Eichelberger M, Huynh-Do, U, Marti,HP Mohaupt MG, Vogt B, Rothen HU, Regl ,B, Takala J, Frey FJ: Comparison of continuous and intermittent renal replacement therapy for acute renal failure. Nephrol Dial Transplant 2005, 20:1630-1637.

11. Vinsonneau C, Camus C, Combes A Costa de Beauregard MA, Klouche K, Boulain T, Pallot JL, Chiche JD, Taupin P, Landais,P, Dhainaut JF: Continuous venovenous haemodiafiltration versus intermittent haemodialysis for acute renal failure in patients with multiple-organ dysfunction syndrome: a multicentre randomised trial. Lancet 2006, 368:379-385.

12. John S, Griesbach D, Baumgartel M, Weihprecht $H$, Schmieder RE, Geiger H: Effects of continuous haemofiltration vs intermittent haemodialysis on systemic haemodynamics and splanchnic regional perfusion in septic shock patients: a prospective, randomized clinical trial. Nephrol Dial Transplant 2001, 16:320-327.
13. Pannu N, Klarenbach S, Wiebe N, Manns B, Tonelli M: Renal replacement therapy in patients with acute renal failure: a systematic review. JAMA 2008, 299:793-805.

14. Rabindranath K, Adams J, Macleod AM, Muirhead N: Intermittent versus continuous renal replacement therapy for acute renal failure in adults. Cochrane Database Syst Rev 2007, 3:CD003773.

15. Bagshaw SM, Berthiaume LR, Delaney A, Bellomo R: Continuous versus intermittent renal replacement therapy for critically ill patients with acute kidney injury: a meta-analysis. Crit Care Med 2008, 36:610-617.

16. Van Biesen W, Lameire N, Vanholder R: A tantalizing question: Ferrari or Rolls Royce? A meta-analysis on the ideal renal replacement modality for acute kidney injury at the intensive care unit. Crit Care Med 2008, 36:649-650.

17. Misset B, Timsit JF, Chevret S, Renaud B, Tamion F, Carlet J: A randomized cross-over comparison of the hemodynamic response to intermittent hemodialysis and continuous hemofiltration in ICU patients with acute renal failure. Intensive Care Med 1996, 22:742-746.

18. van der Sande FM, Gladziwa U, Kooman JP, Bocker G, Leunissen KM: Energy transfer is the single most important factor for the difference in vascular response between isolated ultrafiltration and hemodialysis. J Am SoC Nephrol 2000, 11:1512-1517.

19. Kooman J, Basci A, Pizzarelli F, Canaud B, Haage P, Fouque D, Konner K, Martin-Malo A, Pedrini L, Tattersall J, Tordoir J, Vennegoor M, Wanner C, ter Wee P, Vanholder R: EBPG guideline on haemodynamic instability. Nephrol Dial Transplant 2007, 22(Suppl 2):ii22-ii44.

20. Lameire N, Van Biesen W, Vanholder R: Acute renal failure. Lancet 2005, 365:417-430.

21. Kelleher SP, Robinette JB, Miller F, Conger JD: Effect of hemorrhagic reduction in blood pressure on recovery from acute renal failure. Kidney Int 1987, 31:725-730.

22. Conger JD, Schultz MF, Miller F, Robinette JB: Responses to hemorrhagic arterial pressure reduction in different ischemic renal failure models. Kidney Int 1994, 46:318-323.

23. Tonelli M, Manns B, Feller-Kopman D: Acute renal failure in the intensive care unit: a systematic review of the impact of dialytic modality on mortality and renal recovery. Am J Kidney Dis 2002, 40:875-885.

24. Bell M, Granath F, Schon S, Ekbom A, Martling CR: Continuous renal replacement therapy is associated with less chronic renal failure than intermittent haemodialysis after acute renal failure. Intensive Care Med 2007, 33:773-780.

25. Uchino S, Bellomo R, Kellum JA, Doig G S, Morimatsu H, Morgera S, Schetz M, Tan I, Bouman C, Macedo E, Gibney N, Tolwani A, Ronco C: Patient and kidney survival by dialysis modality in critically ill patients with acute kidney injury. Int J Artif Organs 2007, 30:281-292.

26. Jacka MJ, Ivancinova X, Gibney RT: Continuous renal replacement therapy improves renal recovery from acute renal failure. Can J Anaesth 2005, 52:327-332.

27. Clark WR, Mueller BA, Alaka KJ, Macias WL: A comparison of metabolic control by continuous and intermittent therapies in acute renal failure. J Am Soc Nephrol 1994, 4:1413-1420.

28. Heering P, Morgera S, Schmitz FJ, Schmitz G, Willers R, Schultheiss HP, Strauer $\mathrm{BE}$, Grabensee B: Cytokine removal and cardiovascular hemodynamics in septic patients with continuous venovenous hemofiltration. Intensive Care Med 1997, 23:288-296.

29. De Vriese AS, Colardyn FA, Philippe JJ, Vanholder RC, De Sutter JH, Lameire $\mathrm{NH}$ : Cytokine removal during continuous hemofiltration in septic patients. J Am Soc Nephrol 1999, 10:846-853.

30. Palevsky PM, Zhang JH, O'Connor TZ, Chertow GM, Crowley ST, Choudhury D, Finkel K, Kellum JA, Paganini E, Schein RM, Smith MW, Swanson KM; Thompson BT, Vijayan A, Watnick S, Star RA, Peduzzi P: Intensity of renal support in critically ill patients with acute kidney injury. N Engl J Med 2008 , 359:7-20.

31. Vesconi S, Cruz DN, Fumagalli R, Kindgen-Milles D, Monti G, Marinho A, Mariano F, Formica M, Marchesi M, Rene R, Livigni S, Ronco C: Delivered dose of renal replacement therapy and mortality in critically ill patients with acute kidney injury. Crit Care 2009, 13:R57.

32. Van Werth R, Friedrich JO, Scales DC, Wald R, Adhikari NK: High-dose renal replacement therapy for acute kidney injury: systematic review and metaanalysis. Crit Care Med 2010, 38:1360-1369.

33. Farese S, Jakob SM, Kalicki R, Frey FJ, Uehlinger DE: Treatment of acute renal failure in the intensive care unit: lower costs by intermittent dialysis than continuous venovenous hemodiafiltration. Artif Organs 2009, 33:634-640. 
34. Davenport A, Will EJ, Davison AM: Effect of renal replacement therapy on patients with combined acute renal and fulminant hepatic failure. Kidney Int Supp/ 1993, 41:S245-S251.

35. Davenport A, Will EJ, Davidson AM: Improved cardiovascular stability during continuous modes of renal replacement therapy in critically ill patients with acute hepatic and renal failure. Crit Care Med 1993, 21:328-338.

36. Davenport A: Renal replacement therapy in the patient with acute brain injury. Am J Kidney Dis 2001, 37:457-466.

37. Gabriel DP, Caramori JT, Martim LC, Barretti P, Balbi AL: High volume peritoneal dialysis vs daily hemodialysis: a randomized, controlled trial in patients with acute kidney injury. Kidney Int Supp/ 2008, 73(Suppl 108):S87-S93.

38. Phu NH, Hien TT, Mai NT, Chau TT, Chuong LV, Loc PP, Winearls C, Farrar J, White N, Day N: Hemofiltration and peritoneal dialysis in infectionassociated acute renal failure in Vietnam. N Engl J Med 2002, 347:895-902.

39. Kruczynski K, Irvine-Bird K, Toffelmire EB, Morton AR: A comparison of continuous arteriovenous hemofiltration and intermittent hemodialysis in acute renal failure patients in the intensive care unit. ASAIO J 1993, 39:M778-M781.

40. Klarenbach S, Manns B, Pannu N, Clement FM, Wiebe N, Tonelli M: Economic evaluation of continuous renal replacement therapy in acute renal failure. Int J Technol Assess Health Care 2009, 25:331-338.

41. Rauf AA, Long KH, Gajic O, Anderson SS, Swaminathan L, Albright RC: Intermittent hemodialysis versus continuous renal replacement therapy for acute renal failure in the intensive care unit: an observational outcomes analysis. J Intensive Care Med 2008, 23:195-203.

42. Manns B, Doig CJ, Lee H, Dean S, Tonelli M, Johnson D, Donaldson C: Cost of acute renal failure requiring dialysis in the intensive care unit: clinical and resource implications of renal recovery. Crit Care Med 2003, 31:449-455.

43. Srisawat N, Lawsin L, Uchino S, Bellomo R, Kellum JA: Cost of acute renal replacement therapy in the intensive care unit: results from The Beginning and Ending Supportive Therapy for the Kidney (BEST Kidney) Study. Crit Care 2010, 14:R46

44. Bellomo R, Cass A, Cole L, Finfer S, Gallagher M, Lo S, McArthur C, McGuinness S, Myburgh J, Norton R, Scheinkestel C: Intensity of continuous renalreplacement therapy in critically ill patients. N Engl J Med 2009, 361:1627-1638

45. Abramson S, Niles JL: Anticoagulation in continuous renal replacement therapy. Curr Opin Nephrol Hypertens 1999, 8:701-707.

46. Gabutti L, Marone C, Colucci G, Duchini F, Schonholzer C: Citrate anticoagulation in continuous venovenous hemodiafiltration: a metabolic challenge. Intensive Care Med 2002, 28:1419-1425.

47. Oudemans-van Straaten HM, Bosman RJ, Koopmans M, van der Voort PH; Wester J P, van der Spoel JI, Dijksman LM, Zandstra DF: Citrate anticoagulation for continuous venovenous hemofiltration. Crit Care Med 2009, 37:545-552.

48. Kumar VA, Yeun JY, Depner TA, Don BR: Extended daily dialysis vs. continuous hemodialysis for ICU patients with acute renal failure: a twoyear single center report. Int J Artif Organs 2004, 27:371-379.

49. Vanholder RC, Ringoir SM: Adequacy of dialysis: a critical analysis. Kidney /nt 1992, 42:540-558.

50. Vanholder R, Sever MS, Erek E, Lameire N: Rhabdomyolysis. J Am Soc Nephrol 2000, 11:1553-1561.
51. Sever MS, Erek E, Vanholder R, Yurugen B, Kantarci G, Yavuz M, Ergin H, Bozfakioglu S, Dalmak S, Tulbek MY, Kiper H, Lameire N: Renal replacement therapies in the aftermath of the catastrophic Marmara earthquake. Kidney Int 2002, 62:2264-2271.

52. Vanholder R, Sever MS, De SM, Erek E, Lameire N: Intervention of the Renal Disaster Relief Task Force in the 1999 Marmara, Turkey earthquake. Kidney Int 2001, 59:783-791.

53. Fieghen $H$, Wald $R$, Jaber BL: Renal replacement therapy for acute kidney injury. Nephron Clin Pract 2009, 112:c222-c229.

54. Berbece AN, Richardson RM: Sustained low-efficiency dialysis in the ICU: cost, anticoagulation, and solute removal. Kidney Int 2006, 70:963-968.

55. Kielstein JT, Kretschmer U, Ernst T, Hafer C, Bahr MJ, Haller H, Fliser D: Efficacy and cardiovascular tolerability of extended dialysis in critically ill patients: a randomized controlled study. Am J Kidney Dis 2004, 43:342-349.

56. Marshall MR, Ma T, Galler D, Rankin AP, Williams AB: Sustained low-efficiency daily diafiltration (SLEDD-f) for critically ill patients requiring renal replacement therapy: towards an adequate therapy. Nephrol Dial Transplant 2004, 19:877-884.

57. Baldwin I, Naka T, Koch B, Fealy N, Bellomo R: A pilot randomised controlled comparison of continuous veno-venous haemofiltration and extended daily dialysis with filtration: effect on small solutes and acid-base balance. Intensive Care Med 2007, 33:830-835.

58. Baldwin I, Bellomo R, Naka T, Koch B, Fealy N: A pilot randomized controlled comparison of extended daily dialysis with filtration and continuous veno-venous hemofiltration: fluid removal and hemodynamics. Int J Artif Organs 2007, 30:1083-1089.

59. Lonnemann G, Floege J, Kliem V, Brunkhorst R, Koch KM: Extended daily veno-venous high-flux haemodialysis in patients with acute renal failure and multiple organ dysfunction syndrome using a single path batch dialysis system. Nephrol Dial Transplant 2000, 15:1189-1193.

60. Kielstein JT, Lorenzen J, Kaever V, Burhenne H, Broll M, Hafer C, Burkhardt O: Risk of underdosing of ampicillin/sulbactam in patients with acute kidney injury undergoing extended daily dialysis - a single case. Nephrol Dial Transplant 2009, 24:2283-2285.

61. Kielstein JT, Eugbers C, Bode-Boeger SM, Martens-Lobenhoffer J, Haller H, Joukhadar C, Traunmuller F, Knitsch W, Hafer C, Burkhardt O: Dosing of daptomycin in intensive care unit patients with acute kidney injury undergoing extended dialysis-a pharmacokinetic study. Nephrol Dial Transplant 2010, 25:1537-1541.

62. Pea F, Viale P, Pavan F, Furlanut M: Pharmacokinetic considerations for antimicrobial therapy in patients receiving renal replacement therapy. Clin Pharmacokinet 2007, 46:997-1038.

63. Kuang D, Verbine A, Ronco C: Pharmacokinetics and antimicrobial dosing adjustment in critically ill patients during continuous renal replacement therapy. Clin Nephrol 2007, 67:267-284.

64. Bouman CS: Antimicrobial dosing strategies in critically ill patients with acute kidney injury and high-dose continuous veno-venous hemofiltration. Curr Opin Crit Care 2008, 14:654-659.

doi:10.1186/cc9345

Cite this article as: Vanholder $\mathrm{R}$, et al.: Pro/con debate: Continuous versus intermittent dialysis for acute kidney injury: a never-ending story yet approaching the finish? Critical Care 2011, 15:204. 